\title{
An Engineering Design Study of the Transfer Bridge for the SSC SDC Detector*
}

\author{
J. Western and G. Tulk \\ Superconducting Super Collider Laboratory ${ }^{\dagger}$ \\ 2550 Beckleymeade Ave. \\ Dallas, TX 75237 \\ L. Dittert \\ ICF Kaiser Engineers, Inc. \\ 1800 Harrison Street \\ Oakland, CA 94612
}

May 1993

*Presented at the Fifth Annual International Symposium on the Super Collider, May 6-8, 1993 San Francisco, CA.

tOperated by the Universities Research Association, Inc., for the U.S. Department of Energy under Contract No. DE-AC35-89ER40486. 


\title{
AN ENGINEERING DESIGN STUDY OF THE TRANSFER BRIDGE FOR THE SSC SDC DETECTOR
}

\author{
J. L. Western, PE, SE, ${ }^{1}$ G. W. Tulk, $P E,^{2}$ and L. I. Dittert, $\mathrm{PE}^{3}$ \\ ${ }^{1}$ Conventional Construction Division \\ 2Physics Research Division \\ Superconducting Super Collider Laboratory* \\ 2550 Beckleymeade Avenue \\ Dallas, Texas 75237 \\ 3Principal Engineer \\ ICF Kaiser Engineers, Inc. \\ 1800 Harrison Street \\ Oakland, California 94612
}

\begin{abstract}
The transfer bridge is a major structural installation component for the large detector proposed by the Solenoidal Detector Collaboration (SDC). The transfer bridge is the structural device that allows for installation of the Muon Forward Toroid (MFT) and calorimeter components into the Muon Barrel Toroid (MBT). This paper summarizes the design and construction of the SDC transfer bridge.
\end{abstract}

\section{INTRODUCTION}

The SDC detector is a major SSC experiment located at the IR8 site of the east campus. The total weight of the detector will be approximately 32,000 metric tons.

The Muon Barrel Toroid (MBT) is the primary support mechanism for most components of the SDC detector such as the Muon Forward Toroid (MFT) and Barrel and End Cap Calorimeters.

Each MFT has a weight of about 3,000 metric tons. One is located at each end of the MBT. The MFT is designed to be moved in and out of the MBT to facilitate access to the detector components located inside the MBT (Figure 1).

Each half of the Barrel Calorimeter weighs 1,200 metric tons and each of the End Cap Calorimeters weigh about 600 metric tons. They are located inside the MBT and are designed to be moved in and out of the MBT for detector assembly, repair and/or modifications (Figure 1).

\footnotetext{
* Operated by the Universities Research Association, Inc., for the U. S. Department of Energy under Contract No. DE-AC35-89ER40486.
} 
The principal objective of the transfer bridge design is to develop a removable, easy to assemble, and structurally safe transfer bridge that will permit the movement of the MFT and the Barrel and End Cap Calorimeters between the operating floor and the MBT.

\section{GENERAL DESCRIPTION}

The transfer bridge will consist of two main structures: the support grillage and the bridge girder assembly, and two cantilever walkways weighing a total of about 85 metric tons. Each component of the transfer bridge will be installed by the hall crane between the ends of the MBT and the operating floor.

The columns and bracing of the support grillage will be fabricated from standard structural shapes and the bridge deck will be made up of two braced box girders and heavy floor plates (Figure 1). Two removable cantilevered walkways outboard of the bridge deck will also be provided. The floor plates will be designed to permit small mobile equipment such as fork lifts, welding machines, etc. to access the detector, and the top flange of the box girders will serve as the track plates for rolling the MFT and the calorimeters into the detector.
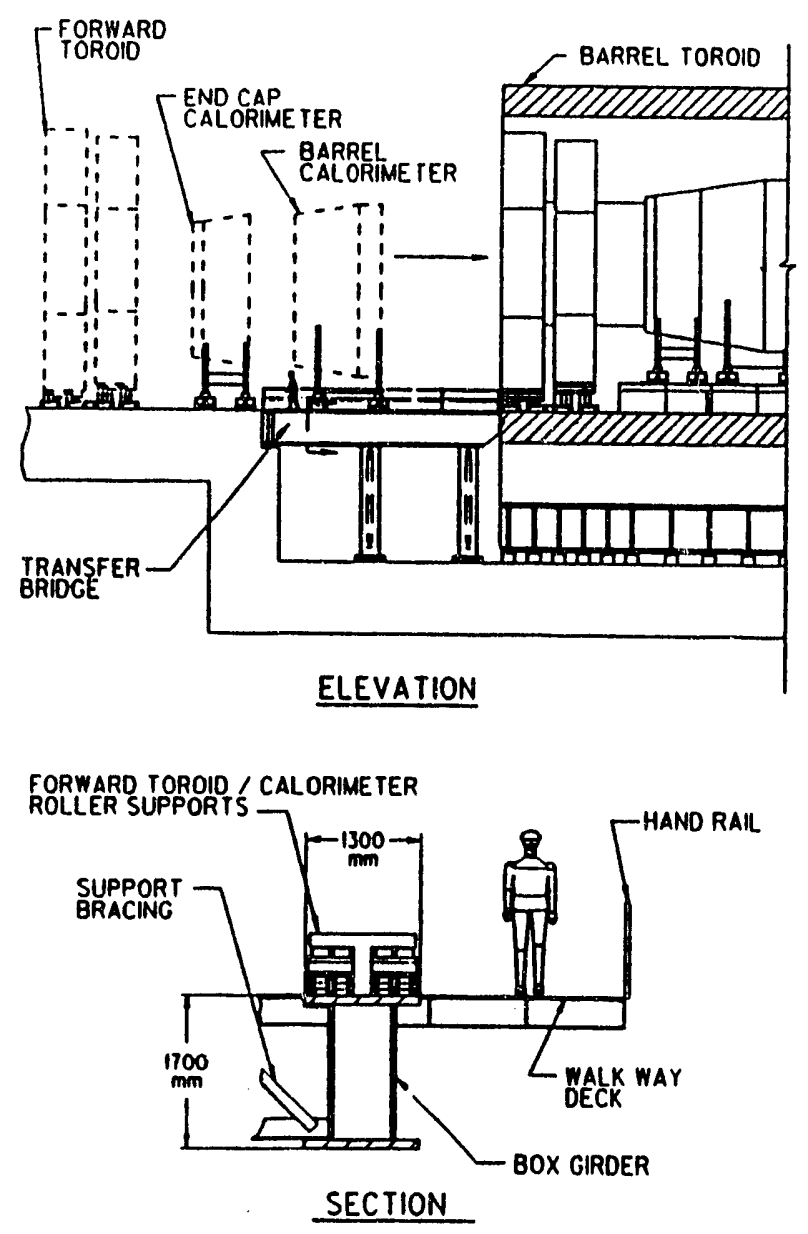

Figure 1. Top figure: illustrates bridge elevation. Bottom figure: illustrates section at box girder.

\section{SPECIAL DESIGN REQUIREMENTS}

The SDC Detector, due to MBT plate block construction, will not be able to support large concentrated transfer loads and will be sensitive to local deflections greater than a few millimeters. The transfer bridge interface with the MBT will be designed to limit loads transferred, as well as match stiffness at this interface to limit deflection differentials. 


\section{BRIDGE GIRDER CONSTRUCTION}

As shown in Figure 1, the bridge girders will be fabricated from four thick plates welded together to form a box girder. The top flange of the girder will be grooved to act as roller guides. The main reasons for using a box girder design will be to permit lowering of the MFT onto the transfer bridge, to adjust or repair the rollers during transit of the MFT, and to reduce the transverse bending and twisting of the top flange due to the roller loading. Due to rolier orientation, the minimum flange width will be $1074 \mathrm{~mm}$ plus the edge distance required.

The two box girders will be tied together with wide flange beams and bracing to prevent rotation and to maintain the gage of the track grooves at all times. A floor plate, level with the top flange of the girders, as well as several lifting lugs for the crane will also be provided. The weight of the completed bridge girder assembly will be about 71 metric tons.

The box girder will have welded stiffeners and bearing plates at the operating floor end, and thick end plates with horizontal shear pins welded to them at the MBT end.

\section{BRIDGE SUPPORT GRILLAGE}

The box girders will be supported at the operating floor and at two other locations by a grillage. The grillage will be a simple welded space frame built from standard rolled shapes. The four columns of the grillage will rest on base plates bearing on the detector basement floor. The weight of the grillage will be about 70 metric tons.

\section{DESIGN ANALYSIS}

A three-dimensional model was created to determine the stresses, deflections, and support reactions of the transfer bridge subjected by the roller loads of the MFT moving across the bridge.

To find the maximum deflections, stresses, and reactions the model was subjected to several loading positions to represent the MFT moving across the bridge. The results indicated that to reduce girder deflections and loading on the shear pins, the columns of the grillage must be larger than what would be required for stability alone.

Not considering the movement of the concrete floor slab, the maximum deflection of the box girder was $1.5 \mathrm{~mm}$. More importantly, the maximum vertical distortion on a 3.5 meter length of the track (the length of the roller train under the MFT) was calculated to be only $1.0 \mathrm{~mm}$.

\section{INSTALLATION}

First, the transfer bridge support grillage will be placed on the basement floor of the detector hall. Then, the girder assembly will be installed on top of the grillage by sliding it forward and dropping the girders into the pockets of the operating floor. In the next step, horizontal hydraulic jacks in the floor pockets will move the girder assembly towards the MBT until the shear pins are fully engaged with the holes in the last plate of the MBT. The collar nuts of the jacks will be locked to ensure that the longitudinal force of the MFT moving jacks will not displace the girders.

In the final step, the support grillage will be jacked up against the box girders for full bearing, and the base plate of the grillage will be grouted to plates embedded in the concrete floor using a quick-setting flowable grout.

The removable walkways outboard of the box girder will be installed to provide access around the MFT moving jacks.

\section{INTERFACE WITH MBT, MFT, CALORIMETERS, AND HALL FLOOR}

At the ends of the MBT, two areas will be kept clear of all piping, cables, etc. to permit butting of the bridge girders.

The details and gage of the roller guide grooves in the top flange of the box girders (used as track plates) must be coordinated with the roller designs of the MFT and the 
calorimeter installation frame. The transition details of the track plates at each end of the bridge must be also coordinated.

The size, elevation, and details of the four plates embedded in the concrete floor for the grillage columns, and the details of the box girder supports at the edge of the operating floor have to be developed for the Architect/Engineer designing the Experimental Hall.

Most importantly, bridge loadings for the MFT, End Cap and Barrel Calorimeter installation frames, and for mobile equipment to be used for installation or maintenance of detector components must be established.

\section{MATERIAL SPECIFICATIONS}

Materials Specification for the transfer bridge and support grillage follows:

- Plates and shapes for bridge assembly, except girder top flanges

- ASTM A36 material.

- Girder top flanges - ASTM A514 material.

- Plates and shapes for grillage - ASTM A36 material.

\section{TOLERANCES}

Tolerances for the transfer bridge and support grillage fabrication will be in accordance with the American Institute Steel Construction (AISC) Specifications for the Design, Fabrication, and Erection of Structural Steel for Buildings, except as follows:

- Tolerance for the working lines of individual columns of the grillage will be 1:1000

- Track plate groove gage tolerance will be $+/-3 \mathrm{~mm}$

- Track plates, including the top flange of the box girders will have a flatness tolerance of $3 \mathrm{~mm}$ on any 5 meter length of track, and will be level across the tracks to a tolerance of $1: 1000$

- Tolerance for track plate elevations will be $+/-3 \mathrm{~mm}$

\section{CONCLUSION}

The transfer bridge will be a major structural component for assembly and disassembly of the SDC Detector, with the detector itself sensitive to the transfer bridge performance. The relative stiffness of the SDC Detector and transfer bridge interface needs to be considered in the design of the transfer bridge.

\section{ACKNOWLEDGMENTS}

The authors would like to acknowledge the contribution of R. Gates in preparation of this paper.

\section{REFERENCES}

Leung, K. K. and Western, J. L., 1992, An Engineering Design Study of Detector Deformation Limits in the SDC - Detector, in: "IISSC Supercollider 4," pp. 167-174 Plenum Press, New York.

Western, J. L. and Butalla, M. W., 1992, SDC Detector Foundation Requirements, in: "IISSC Supercollider 4," pp. 1119-1125 Plenum Press, New York.

Dittert, Les, 1992, "SDC Forward Toroids Transfer Design Conceptual Design," ICF Kaiser Engineers, Inc., California. 

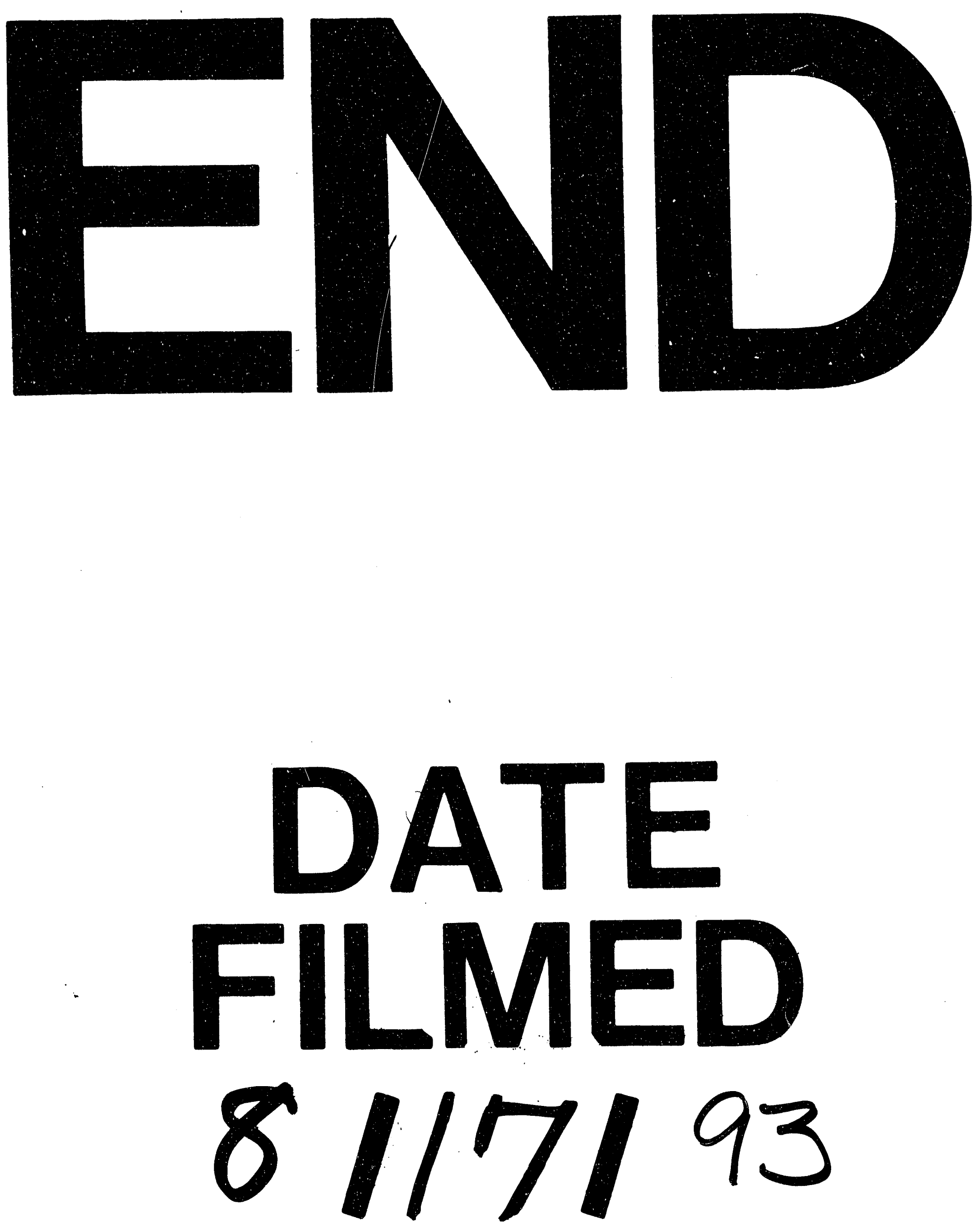

1 
